\title{
Nilai-nilai Pendidikan Akhlak Terkait Keutamaan Rasa Malu dalam Kitab Adab Riyadhush Shalihin
}

\author{
Ira Solihah*, Ikin Asikin \\ Islam Bandung, Indonesia. \\ *irasolihah13@gmail.com, asikin@yahoo.co.id
}

Prodi Pendidikan Agama Islam, Fakultas Tarbiyah dan Keguruan, Universitas

\begin{abstract}
The purpose of this study was to determine the values of moral education related to the virtue of shame in the book of adab riyadhush shalihin written by Imam An-Nawawi. This study applies a qualitative descriptive approach using the library research method. Based on the literature study, there are several sources of study, namely primary sources in the form of the book of Riyadhush Shalihin and secondary sources that support this research, information contained in the library and other information. In data analysis using content analysis, namely the method used to draw conclusions through efforts to find the content of the message which is carried out objectively and systematically so that it can be a conclusion that answers the formulation of the problem. This study tries to answer the questions: 1 . The essence of education in the book of adab riyadhush shalihin related to the virtue of shame; 2 . The concept of strengthening shame character education according to experts; 3 . The educational values contained in the book of adab riyadhush shalihin are related to the virtue of shame towards strengthening the character of shame in the personal, community and state spheres. Through content analysis, several points are made. First, the essence of education from the book of adab riyadush shalihin is to cultivate a sense of faith in oneself, that faith will bring forth shame by itself, and shame brings nothing but goodness. Second, the concept of strengthening shame character education is a process in the formation and development of the potential that exists within the individual with the aim of protecting him from disgraceful acts. Third, there are 3 parts of the value of education in the book of adab riyadhush shalihin related to the virtue of shame on character strengthening, namely for oneself, the scope of society and the life of the nation and state.
\end{abstract}

Keywords: Value, Education, Morals, Shame, Riyadhush Shalihin.

\begin{abstract}
Abstrak. Tujuan penelitian ini adalah untuk mengetahui nilai-nilai pendidikan akhlak terkait keutamaan rasa malu dalam kitab adab riyadhush shalihin yang ditulis oleh Imam An-Nawawi. Penelitian ini menerapkan pendekatan deskriptif kualitatif dengan menggunakan metode library research atau penulisan berdasarkan literatur. Berdasarkan studi kepustakaan terdapat beberapa sumber kajian yaitu sumber primer berupa kitab riyadhush shalihin dan sumber sekunder yang menjadi pendukung dalam penelitian ini, informasi yang terdapat di perpustakaan dan informasi lainnya. Dalam analisis data menggunakan analisis isi (content analysis) yang mana merupakan cara yang digunakan untuk menarik kesimpulan melalui usaha menemukan kandungan isi pesan yang dilakukan dengan objektif dan sistematis sehingga dapat menjadi kesimpulan yang menjawab rumusan masalah. Penelitian ini berusaha menjawab pertanyaan : 1. Esensi kependidikan dalam kitab adab riyadhush shalihin terkait keutamaan rasa malu; 2 . Konsep penguatan pendidikan rasa malu menurut para ahli; 3. Nilai-nilai pendidikan yang terkandung dalam kitab adab riyadhush shalihin terkait keutamaan rasa malu terhadap penguatan rasa malu dalam ruang lingkup pribadi, masyarakat dan negara. Melalui analisis isi dihasilkan beberapa poin. Pertama, esensi kependidikan dari kitab adab riyadush shalihin adalah dengan menumbuhkan rasa iman dalam diri, iman tersebut akan memunculkan rasa malu dengan sendirinya, dan rasa malu tidak membawa apapun selain kebaikan. Kedua, konsep penguatan pendidikan rasa malu adalah sebuah proses dalam pembentukan serta pengembangan potensi yang ada dalam diri individu dengan tujuan melindungi mereka dari melakukan suatu hal yang tercela. Ketiga, terdapat 3 bagian nilai pendidikan dalam kitab adab riyadhush shalihin terkait keutamaan rasa malu terhadap penguatan karakter yakni untuk dirinya sendiri, ruang lingkup masyarakat serta kehidupan berbangsa dan bernegara.
\end{abstract}

Kata Kunci: Nilai, Pendidikan, Akhlak, Malu, Riyadhush Shalihin. 


\section{A. Pendahuluan}

Kenyataan dan problematika yang terjadi dimasyarakat Muslim kian harinya makin beragam. Salah satu permasalahannya adalah terkait krisis rasa malu yang dimiliki oleh masyarakat Muslim di negara Indonesia. Pemahaman masyarakat Muslim Indonesia secara keseluruhan terkait keutamaan rasa malu ini nampaknya sangat minim. Dengan berbagai kasus mulai dari banyaknya anak muda yang melakukan prank sehingga merugikan orang lain, lalu semakin bebasnya akses budaya luar yang kurang baik memasuki negara ini dan banyak ditiru oleh masyarakat. Hal tersebut membuktikan bahwa rasa malu yang dimiliki masyarakat Muslim khususnya Indonesia semakin menipis.

Pada masa sekarang, dunia pendidikan di Indonesia juga sedang mengalami hal genting terlebih saat wabah seperti ini. Terdapat banyak kasus degradasi akhlak yang terjadi di khususnya di sekolah. Beberapa contohnya yaitu peserta didik yang menyontek ketika ujian, membolos saat kelas sudah dimulai, tidak memiliki sopan santun terhadap guru dan sebagainya. Masalah tersebut terjadi disebabkan oleh kurangnya pendidikan rasa malu pada peserta didik. Sehingga sangat dibutuhkan penguatan pendidikan karakter yang bisa dimulai dari keluarga, masyarakat serta sekolah (Suryanti, E. W.; Widayanti, 2018).

Masyarakat kita yang memiliki budaya kurang kritis dalam mempelajari dan menerima sesuatu, mengakibatkan kurang tergalinya nilai-nilai pendidikan yang terdapat dalam kitab riyadhush shalihin khususnya dalam bagian kitab Adab Bab "Keutamaan Malu dan Anjuran untuk Menghiasi Diri Dengannya". Dengan menggali nilai-nilai pendidikan akhlak dalam kitab tersebut diharapkan mampu menjadi penguat dalam pendidikan yang bisa dimulai dari diri individu, khususnya rasa malu.

Berdasarkan latar belakang yang telah diuraikan, maka perumusan masalah dalam penelitian ini sebagai berikut:

1. Bagaimana esensi kependidikan dari hadis-hadis dalam kitab adab riyadhush shalihin terkait keutamaan rasa malu?

2. Bagaimana konsep penguatan pendidikan rasa malu menurut para ahli?

3. Bagaimana nilai-nilai pendidikan yang terkandung dalam kitab adab riyadhush shalihin terkait keutamaan rasa malu terhadap penguatan rasa malu dalam ruang lingkup pribadi, masyarakat dan negara?

Selanjutnya, tujuan dalam penelitian ini diuraikan dalam pokok-pokok sebagai berikut

1. Menggali esensi kependidikan dalam kitab adab riyadhush shalihin terkait keutamaan rasa malu.

2. Menemui konsep penguatan pendidikan rasa malu menurut para ahli.

3. Mengetahui nilai-nilai pendidikan yang terkandung dalam kitab adab riyadhush shalihin terkait keutamaan rasa malu terhadap penguatan rasa malu dalam ruang lingkup pribadi, masyarakat dan negara.

\section{B. Metodologi}

Penelitian ini menerapkan pendekatan deskriptif kualitatif. Deskriptif kualitatif merupakan suatu penelitian terkait peristiwa apa saja yang dialami subjek penelitian. Contohnya, sikap atau perbuatannya, motivasi dan lain sebagainya yang dipaparkan melalui kata-kata yang jelas dan bahasa yang mudah dimengerti dengan memanfaatkan dan merujuk berbagai metode alamiah (Moloeng, 2007).

Jenis penelitian yang digunakan ialah penelitian kepustakaan (library research) sebab objek kajian peneliti adalah kitab riyadhush shalihin yang merupakan kajian literatur. Penelitian kepustakaan atau library research adalah suatu kegiatan yang berhubungan dengan pengumpulan data pustaka penelitian. Library research memanfaatkan sumber pustaka untuk memperoleh data penelitian, dengan melakukan kegiatan membaca, mencatat dan mengolah bahan penelitian (Zed, 2008).

Sumber data primer merupakan sumber data yang paling utama digunakan dan sesuai dengan permasalahan dalam penelitian ini. Adapun sumber data primer dalam penelitian ini adalah kitab adab dalam kitab riyadush shalihin. Sumber data sekunder dalam penelitian ini 
ialah kitab yang ada hubungannya dengan karangan Imam Abu Zakaria Yahya bin Syaraf AnNawawi, khusunya kitab riyadhush shalihin. Buku-buku yang berkaitan dengan akhlak baik itu dari jurnal dan dari sumber lainnya pun menjadi rujukan dalam penelitian ini.

Peneliti menggunakan teknik analisis isi atau content analysis. Analisis isi merupakan tahapan kegiatan yang dilaksanakan secara sistematis kemudian disiapkan untuk menguji isi ataupun makna yang terkandung dalam sebuah konteks atau rekaman (Kholil, 2006).

\section{Pembahasan dan Diskusi}

\section{Esensi Kependidikan dari Kitab Adab Riyadhush Shalihin terkait Keutamaan Rasa Malu}

Dalam kitab adab riyadush shalihin khususnya terkait rasa malu terdapat beberapa poin penting, diantaranya:

1. Rasulullah Saw. mengatakan bahwa rasa malu merupakan bagian dari iman. Salah satu fitrah manusia adalah dengan memiliki rasa malu. Bila rasa malu hilang darinya maka manusia bisa berbuat seperti binatang atau bahkan lebih parah.

2. Setiap rasa malu itu tidak mendatangkan hal apapun kecuali kebaikan. Maksudnya dengan memiliki rasa malu kita akan terjaga dari perilaku keji dan cenderung akan lebih sering melakukan kebaikan. Hal tersebut tentunya akan menuntun kita untuk memiliki akhlakul karimah.

3. Imam An-Nawawi menuturkan bahwa hakikat dari rasa malu itu muncul dalam bentuk sikap meninggalkan perbuatan buruk dan perbuatan dzalim. Menurut Nashrullah, seorang sufi besar Imam Junaid menjelaskan bahwa rasa malu muncul dari melihat besarnya nikmat Allah Swt., sedangkan ia merasa banyak kekurangan dalam mengamalkan ketaatan kapada-Nya (Nashrullah, 2020).

Esensi kependidikan dari dalam kitab adab riyadhush shalihin terkait keutamaan rasa malu diantaranya adalah dengan memperkuat iman pada diri individu. Hal tersebut bisa dimulai dengan menanamkan nilai keislaman di rumah, khususnya bagi orang tua terhadap anaknya. Dengan menanamkan nilai tersebut maka itu termasuk pada memperkuat iman kita. Iman yang kuat akan melahirkan rasa malu. Rasa malu tidak mendatangkan apapun kecuali kebaikan, karena dengan rasa malu kita akan menghindarkan diri dari hal-hal yang dilarang oleh Allah Swt.

\section{Konsep Penguatan Pendidikan Rasa Malu menurut Para Ahli}

Menurut Setiawan, dkk. Penguatan Pendidikan Karakter (PPK) merupakan suatu aktivitas dalam pendidikan yang menggambarkan tanggung jawab dari sistem pendidikan guna memperkuat karakter pada peserta didik. Adapun peran Pendidikan Agama Islam menjadi salah satu mata pelajaran yang paling utama untuk memperkuat pendidikan karakter anak negeri khususnya dilingkungan sekolah. Peran mata pelajaran PAI dalam penguatan pendidikan karakter juga menjadi sangat kuat dan strategis. Penerapan penguatan pendidikan karakter melalui mata pelajaran PAI mengakibatkan kebiasaan baru yang diterima oleh peserta didik dalam mengaplikasikan ajaran agama Islam (Setiawan, Farid; Hutami, Annisa Septarea; Riyadi, Dias Syahrul; Arista, Virandra Adhe; Dani, 2021). Dengan pendidikan karakter yang kuat rasa malu akan terbentuk.

Penguatan pendidikan rasa malu merupakan sebuah proses dalam perubahan, pembentukan serta pengembangan potensi yang ada dalam diri individu dengan tujuan melindungi mereka dari melakukan suatu hal yang kurang baik. Hal tersebut berarti penguatan pendidikan rasa malu ini adalah agar kita lebih mendekatkan diri kepada Allah Swt. dan menjauhi segala larangan-Nya.

\section{Nilai- Nilai Pendidikan Akhlak dalam Kitab Adab Riyadhush Shalihin terkait Keutamaan Rasa Malu terhadap Penguatan Rasa Malu dalam Ruang Lingkup Pribadi, Masyarakat dan Negara}

Nilai- nilai pendidikan yang terkandung dalam kitab adab riyadhush shalihin terkait keutamaan rasa malu diantaranya: 
1. Rasa Malu kepada Allah Swt.

Malu kepada Allah Swt. merupakan sikap malu terbaik yang dapat membawa kebahagiaan hidup dunia dan akhirat. Manusia yang memiliki rasa malu kepada Allah Swt. tidak akan berani melakukan kejahatan dan meninggalkan kewajibannya. Mereka meyakini bahwa Allah Swt. tak pernah tidur dan Maha melihat setiap hal yang dilakukan hamba-Nya (Anwar, 2020).

2. Rasa Malu terhadap Sesama Manusia

Rasa malu terhadap sesama manusia sangat penting karena hal tersebut dapat mengendalikan diri agar tidak melampaui batas dan ajaran agama. Walaupun dengan rasa malu tersebut mereka tidak akan memperoleh pahala sempurna karena rasa malunya bukan semata-mata karena Allah Swt. Namun, rasa malu seperti ini dapat memberikan kebaikan baginya dari Allah Swt. karena ia terjaga dari perbuatan tercela (Anwar, 2020).

3. Rasa Malu terhadap Diri Sendiri

Rasa malu terhadap diri sendiri perlu kita miliki, terlebih ketika kita sedikit melakukan amal saleh dihadapan Allah Swt. dan kebaikan untuk umat dibandingkan orang lain (Anwar, 2020). Rasa malu perlu ditunjukan seorang Muslim dalam semua aktivitas kehidupan. Melalui sifat malu, seseorang dapat menjaga diri dari perbuatan hina, keji dan tercela. Lewat rasa malu, seseorang akan juga berusaha mendapat rezeki yang halal dan akan merasa menyesal jika tidak dapat melakukan kebaikan setiap hari (Anwar, 2020).

Dengan penjelasan tersebut diharapkan masyarakat bisa lebih memperkuat karakter yang nantinya terwujud dalam rasa malu pada kehidupan pribadi, bermasyarakat dan bernegara.

Menurut Lyta Permatasari (Permatasari, 2016) menyebutkan bahwa hasil yang ingin didapatkan dalam penguatan karakter adalah dengan terbentuknya masyarakat yang bersikap dan bertingkah laku secara santun. Salah satu cara agar kita memiliki sikap tersebut adalah dengan menerapkan rasa malu dalam kehidupan sehari-hari. Secara rinci dapat dijelaskan bahwa penguatan rasa malu tersebut untuk dapat menghasilkan masyarakat yang memiliki:

1. Keimanan dan ketakwaan yang kuat terhadap Allah Swt.

2. Sikap dan tingkah laku yang menjunjung tinggi harkat dan martabat manusia sebagai makhluk ciptaan Allah Swt. dengan saling menghargai dan menghormati satu sama lain.

3. Pengetahuan, sikap, perilaku dan kemampuan dalam menerapkan rasa malu dalam kehidupan bermasyarakat, berbangsa dan bernegara.

Ada 3 pilar utama untuk mewujudkan nilai-nilai pendidikan terkait keutamaan rasa malu dalam penguatan karakter, diantaranya:

1. Ruang Lingkup Individu

Nilai- nilai pendidikan yang terkandung dari kitab adab riyadhush shalihin terkait keutamaan rasa malu terhadap penguatan rasa malu dalam ruang lingkup pribadi sangatlah banyak. Diantara nilai-nilai tersebut dapat membentuk pribadi yang lebih baik. Hal tersebut menjadikan kita pribadi yang ber-akhlakul karimah, yakni pribadi yang memiliki habluminallah dan hablum minannaas yang baik. Nilai tersebut nantinya terwujud dalam perilaku dan diterapkan dalam kehidupan sehari-hari secara konsisten.

2. Ruang Lingkup Masyarakat

Terdapat beberapa nilai pendidikan yang terkandung dari kitab adab riyadhush shalihin terkait keutamaan rasa malu terhadap penguatan rasa malu dalam ruang lingkup masyarakat. Dengan saling menghargai dan menghormati satu sama lain, tidak berucap kata-kata yang menyakiti sesamanya dan membicarakan hal yang baik terhadap saudaranya menjadi ikhtiar kita dalam menerapkan rasa malu dalam kehidupan bermasyarakat. Alasan kita harus menerapkan nilai tersebut karena lingkungan masyarakat adalah lingkungan yang kita jumpai setiap hari. Sudah sepatutnya demi terbentuk hablum minannaas yang baik kita tdiak boleh berselisih satu sama lain.

3. Ruang Lingkup Berbangsa dan Bernegara

Terkandung segenap nilai pendidikan yang terdapat dalam kitab adab riyadhush shalihin terkait keutamaan rasa malu terhadap penguatan rasa malu dalam ruang lingkup berbangsa dan bernegara. Dalam kehidupan berbangsa dan bernegara terjadi kontrak 
sosial atau perasaan solidaritas untuk mendukung nilai-nilai luhur yang ada. Dengan menerapkan rasa malu dikehidupan berbangsa dan bernegara, negeri ini akan menjadi bangsa yang maju. Rasa malu membuat kita enggan berbuat hal-hal tercela. Masyarakat tidak akan membuang sampah sembarangan, tidak akan korupsi atau mengambil sesuatu yang bukan haknya, bersikap adil terhadap rakyatnya bagi pemimpin dan bersikap patuh pada pemimpin bagi rakyat.

\section{Kesimpulan}

Berdasarkan pembahasan dalam penelitian ini, peneliti menyimpulkan beberapa hasil penelitian sebagai berikut:

1. Esensi kependidikan dari dalam kitab adab riyadhush shalihin terkait keutamaan rasa malu diantaranya adalah dengan memperkuat iman pada diri individu. Hal tersebut bisa dimulai dengan menanamkan nilai keislaman di rumah, khususnya bagi orang tua terhadap anaknya. Dengan menanamkan nilai tersebut maka itu termasuk pada memperkuat iman kita. Iman yang kuat akan melahirkan rasa malu. Rasa malu tidak mendatangkan apapun kecuali kebaikan, karena dengan rasa malu kita akan menghindarkan diri dari hal-hal yang dilarang oleh Allah Swt.

2. Penguatan pendidikan rasa malu merupakan sebuah proses dalam perubahan, pembentukan serta pengembangan potensi yang ada dalam diri individu dengan tujuan melindungi mereka dari melakukan suatu hal yang kurang baik. Hal tersebut berarti penguatan pendidikan rasa malu ini adalah agar kita lebih mendekatkan diri kepada Allah Swt. dan menjauhi segala larangan-Nya.

3. Nilai- nilai pendidikan yang terkandung dalam kitab adab riyadhush shalihin terkait keutamaan rasa malu diantaranya: Rasa Malu kepada Allah Swt.; Rasa Malu terhadap Sesama Manusia; Rasa Malu terhadap Diri Sendiri. Terdapat 3 pilar utama untuk mewujudkan nilai-nilai pendidikan terkait keutamaan rasa malu dalam penguatan karakter. Pertama, dalam ruang lingkup Individu yaitu dengan menjadikan diri lebih baik. Kedua, dalam ruang lingkup masyarakat dengan cara saling menghargai dan menghormati satu sama lain, tidak berucap kata-kata yang menyakiti sesamanya dan membicarakan hal yang baik terhadap saudaranya. Ketiga, dalam ruang lingkup kehidupan berbangsa dan bernegara dengan tidak membuang sampah sembarangan, tidak korupsi atau mengambil sesuatu yang bukan haknya, bersikap adil terhadap rakyatnya bagi pemimpin dan bersikap patuh pada pemimpin bagi rakyat.

\section{Acknowledge}

Alhamdulillah atas izin dan pertolongan Allah Swt. penulis dapat menyelesaikan karya ilmiah ini dengan tepat waktu. Penyusunan karya ilmiah ini juga tidak terlepas dari banyak doa, dukungan, bimbingan dari banyak pihak. Maka dari itu perkenankanlah penulis menyampaikan ucapan terimakasih yang sebesar besarnya:

1. Kepada Bapak Enoh Nuroni, Drs., M. Ag, selaku Dekan Fakultas Tarbiyah dan Keguruan

2. Kepada Bapak Dr. H. Ikin Asikin, Drs. M. Ag, selaku pembimbing I dan Bapak H. Eko Surbiantoro, Drs., M. Pd. I, selaku pembimbing II yang tidak pernah lelah untuk memberi bimbingan, arahan, nasihat, saran dan motivasi sehingga penulis mendapatkan banyak sekali ilmu baru dan pengalaman dalam menyelesaikan skripsi ini

3. Kepada seluruh Dosen dan Staff Fakultas Tarbiyah dan Keguruan Universitas Islam Bandung, yang telah memberikan banyak sekali bekal ilmu dan membantu para mahasiswanya. Semoga dalam setiap langkah bapak dan ibu selalu ada dalam ridho serta lindungan Allah Swt.

4. Kepada seluruh pihak yang membantu penulis dalam penyelesaian penyusunan karya ilmiah ini

Tidak ada kata yang dapat penulis sampaikan selain rasa syukur yang sebesar-besarnya, semoga apa yang telah diberikan oleh semuanya menjadi pahala dan selalu mendapatkan keridaan Allah Swt. kapanpun dan dimanapun semuanya berada.

Aamiin Yaa Rabbal 'Aalamiin 
62 | Ira Solihah, et al.

\section{Daftar Pustaka}

[1] Anwar, R. (2020). Rasa Malu Menggambarkan Kwalitas Keimanan Seorang Muslim. https://badilag.mahkamahagung.go.id/pojok-dirjen/pojok-dirjen-badilag/rasa-malumenggambarkan-kwalitas-keimanan-seorang-muslim

[2] Kholil, S. (2006). Metode Penelitian Komunikasi. Ciptapustaka Media.

[3] Moloeng, L. J. (2007). Metode Penelitian Kualitatif. Remaja Rosda Karya.

[4] Nashrullah. (2020). Rasulullah SAW Ajarkan Umatnya Budayakan Malu, Mengapa? https://www.republika.co.id/berita/q629vn320/rasulullah-saw-ajarkan-umatnyabudayakan-malu-mengapa

[5] Permatasari, L. (2016). Kebangsaan, Membangun Pendidikan dan Membina Karakter Bangsa Berlandaskan Nilai-Nilai. https://bpkad.banjarkab.go.id/index.php/2016/09/27/membangun-pendidikan-danmembina-karakter-bangsa-berlandaskan-nilai-nilai-kebangsaan/

[6] Setiawan, Farid; Hutami, Annisa Septarea; Riyadi, Dias Syahrul; Arista, Virandra Adhe; Dani, Y. H. Al. (2021). Kebijakan Penguatan Pendidikan Karakter Melalui Pendidikan Agama Islam. Al-Mudarris: Jurnal Ilmiah Pendidikan Islam, 1-22.

[7] Suryanti, E. W.; Widayanti, F. D. (2018). Penguatan Pendidikan Karakter Berbasis Religius. Conference on Innovation and Application of Science and Technology, 254-262.

[8] Zed, M. (2008). Metode Penelitian Kepustakaan. Yayasan Obor Indonesia. 